\title{
Conservation Status and Historical Relatedness of South African Communal Indigenous Goat Populations Using Genome-Wide Snp Marker
}

Tlou Caswell Chokoe ( $\nabla$ tlouamin@gmail.com)

Department of Agriculture Land Reform and Rural Development https://orcid.org/0000-0001-69441371

Khanyi Hadebe

Agricultural Research Council-Biotechnology Platform

Farai Muchadeyi

Agricultural Research Council-Biotechnology Platform

Khathutshelo Nephawe

Tshwane University of Technology Faculty of Science

\section{Edgar Dzomba}

University of KwaZulu-Natal School of Life Sciences

\section{Tumudi Mphahlele}

Deprtment of Agriculture Land Reform and Rural Development

\section{Tlou Matelele}

Department of Agriculture Land Reform and Rural Development

\section{Bohani Mtileni}

Tshwane University of Technology Faculty of Science

\section{Research article}

Keywords: runs of homozygosity, effective population size, populations, genomic inbreeding

Posted Date: August 13th, 2020

DOI: https://doi.org/10.21203/rs.3.rs-50797/v1

License: (c) (i) This work is licensed under a Creative Commons Attribution 4.0 International License.

Read Full License 


\section{Abstract}

Background: Indigenous goats forms the majority of populations in smallholder; low input, low output production systems and are considered an important genetic resource due to their adaptability to different production environments and support communal farming. Effective population size $\left(N_{e}\right)$, inbreeding levels, and the runs of homozygosity (ROHs) are effective tools for exploring the genetic diversity and understanding the demographic history in efforts to support breeding strategies to use and conserve genetic resources.

Results: Across populations, the current $N_{e}$ of Gauteng was the lowest at 371 animals, while the historical $N_{e}$ across populations suggests that the ancestor $N_{e}$ has decreased by $53.86 \%, 44.58 \%, 42.16 \%$ and $41.16 \%$ in Free State (FS), North West (NW), Limpopo (LP) and Gauteng (GP), respectively, over the last 971 generations. Genomic inbreeding levels related to ancient kinship $\left(F_{R O H}>5 \mathrm{Mb}\right)$ was highest in FS $(0.08 \pm 0.09)$ and lowest for Eastern Cape $(E C)(0.02 \pm 0.02)$. A total of $871 \mathrm{ROH}$ island regions which include important environmental adaptation and hermo-tolerance genes such as IL10RB, IL23A, FGF9, IGF1, EGR1, MTOR and MAPK3 were identified (occurring in over $20 \%$ of the samples) in FS $(n=37)$, GP $(n=42)$, NW $(n=2)$ populations only. The mean length of ROH across populations was $7.76 \mathrm{Mb}$ and ranged from 1.61 Mb KwaZulu-Natal (KZN) to $98.05 \mathrm{Mb}$ (GP and NW). Distribution of ROH according to their size showed that the majority $(n=1949)$ of the detected ROH were $>5 \mathrm{Mb}$ in length than the other categories. Assuming two hypothetical ancestral populations, the population from KZN and LP are revealed, supporting PC 1. The genomes of KZN and LP shared an origin but have substantial admixture from the EC and NW populations.

Conclusions: These findings indicated a greater negative impact of inbreeding in recent times which is important for planning conservation strategies. It was revealed that the occurrence of high $N_{e}$ and autozygosity varied largely across breeds in communal indigenous goat populations at different recent and ancient events when a genome-wide SNP marker was used.

\section{Background}

There are currently 15 South African goat genetic resources listed on the DAD-IS of FAO and 13 on the Domestic Animal Genetic Resources Information System (DAGRIS) of the International Livestock Research Institute, including those listed in DAD-IS. In the country, indigenous goat ecotypes have been used as triple purpose animals (e.g skin, milk and meat); and depending on the region, the animal characteristics, and the geographical isolations, they began to diverge into breeds/populations [60]. These ecotypes have generally been named after their place of origin (e.g Northern Cape Skilder) and/or their prominent characteristics (e.g Xhosa lobbed ear) and on basis of the people who own them (e.g Nguni) [41]. These ecotypes are widely spread across all major agro-ecological regions of South Africa displaying adaptability traits to a specific habitat or production environment and represent a significant resource to satisfy present and future demands for sustainable farming in a changing environment. 
Improvement of indigenous livestock has been practised through the introduction of high performing breeds (exotic and improved breeds) and as a result of indiscriminate mating and breeding, the majority of village goat populations are crossbreds [39]. The majority of the smallholder farmers have small herds or flocks where herd sizes could be less than five animals with the majority of these herds being nondescript, crossbred or indigenous cattle, sheep and goats [42,47]. The reduction in local indigenous populations suggests a need for conservation of local genetic resources through implementing a national conservation strategy. Various studies conducted in the smallholder communal areas showed average flock sizes of between 1 and 120 goats $[61,14]$. Furthermore, about $70 \%$ of the goats are kept under traditional management systems where the farm structure comprises of about twenty $( \pm 20)$ indigenous goats [43]. Towards this aim, detailed information on the phenotypic, genetic diversity and population structure of goats ecotype populations become important to guide conservation strategies through utilisation of these populations. According to [17], conservation and characterisation of animal genetic resources is critical because of their contribution to the sustainable livelihoods of rural communities that depend on them for food security. Conservation frameworks should incorporate both genetic diversity and breed merits for prioritizing breeds/populations from community to national level to support breeding programs of current populations.

The completion of the first draft of the goat genome [13] made it possible for the development of highdensity markers [59]. The Illumina goat SNP50K BeadChip includes 53347 SNPs [59] that have found utility in South African population genetic studies in Angora [27], commercial, indigenous and village goat populations [37] as well as investigate genetic adaptation to environmental pressures [36]. The use of the tool has been described in other African countries $[48,65]$ and in specialised breeds [32]. While much work on South African commercial, indigenous and village goat populations has focused on genetic studies and investigation on genetic adaptation, less work has focused on conservation status and historical relatedness of communal indigenous goat populations.

The presence of the extent of an effective population size ( $\mathrm{Ne})$, is an important population genetic parameter that has recently received a great deal of research attention [64], determining population demographic development [12] and demographic processes such as migration and admixture [45], and having profound implications for understanding the architecture of the animal genome [27, 3]. In addition, $\mathrm{Ne}$ is widely regarded as one of the most critical population parameters because it measures the rates of genetic drift and inbreeding as well as affects the efficacy of systematic evolutionary forces such as mutation, selection, and migration [56]. It also helps to discover population demographic history and allows for the prediction of the behaviour of genetic diversity through time. The $\mathrm{Ne}$ is estimated using the $r^{2}$ coefficient and measures the observed range and the amount of genetic variation within a frame of population genetics [5]. It also provides information on the degree of inbreeding of the population under consideration [18]. The Ne determines the amount of genetic variation, genetic drift, and linkage disequilibrium (LD) in populations [28]. Implementation of a national conservation strategies for FAnGR must be based on a better understanding on the degree of inbreeding of the populations, genetic variation, genetic drift, and linkage disequilibrium (LD) in populations. 
An increase in inbreeding $(F)$ over generations leads to a reduction in genetic diversity [48]. Higher frequency of homozygous genotypes for deleterious alleles with a reduction in individual performance (inbreeding depression) and lower population viability [49]. When an offspring is inbred, it may inherit autozygous chromosomal segments from both parents that are identical by descent (IBD), i.e., segments that are derived from a common ancestor [8]. The result is continuous homozygous segments in the genome, also known as runs of homozygosity $(\mathrm{ROH})$. The $\mathrm{ROH}$ are contiguous lengths of homozygous segments of the genome where the two haplotypes inherited from the parents are identical [20].

The extent of $\mathrm{ROH}$ can be used to estimate the inbreeding coefficient [7, 30,51], to disclose the genetic relationships among individuals, usually estimating with high accuracy the autozygosity at an individual and/or population level $[16,15]$. Autozygosity is the homozygous state of identical-by descent (IBD) alleles, which can result from several phenomena such as genetic drift, population bottlenecks, mating of close relatives, natural and artificial selection $[11,27]$. The ROH can also be used to establish the level of selection pressure on the populations [63]. Length and frequency of ROHs may also be used to distinguish distant from more recent inbreeding since the length of IBD segments follows an inverse exponential distribution with a mean of $1 / 2 \mathrm{~g}$ Morgans, where $\mathrm{g}$ is the number of generations from a common ancestor [23]. Effective populations $(\mathrm{Ne})$ and ROH have been studied in humans [20], cattle [31, $15,34]$, pigs [56, 1] sheep [33] but less comprehensively in other livestock species, such as goats for designing conservation strategies especially on the communal indigenous goats of South Africa. The objective of this study was to determine the conservation status and historical relatedness of South African communal indigenous goat populations using genome-wide SNP markers.

\section{Results}

\section{Genetic diversity indices.}

Variation of the estimated $N_{e}$ at $t$ generations ago (from 12 to 983 ) is presented in Figure 1. As expected, $N_{e}$ decreased progressively across generations, however, $N_{e}$ was higher than 150 for all breeds at 12 generations ago. The variation in $N_{e}$ across generations was smallest for Gauteng $\left(N_{e}=371\right)$ and Free State $\left(N_{e}=386\right)$ whilst Limpopo had the highest $\left(N_{e}=723\right)$. Ancestral populations exhibited considerably larger $N_{e}$ values, with the largest historical $N_{e}$ values $\left(N_{e}=5772\right)$.

The average inbreeding coefficient $\left(F_{I S}\right)$, was lowest in Free State $\left(F_{I S}=0.03 \pm 0.09\right)$, followed by Gauteng $\left(F_{I S}=0.04 \pm 0.09\right)$, North West $\left(F_{I S}=0.05 \pm 0.01\right)$ and highest in Limpopo $\left(F_{I S}=0.09 \pm 0.05\right)$. Overall, the inbreeding level was $0.06 \pm 0.08$. The average $F_{R O H}$, its range of variation across populations and its distribution are summarised in Table1. Genomic inbreeding coefficients $\left(F_{R O H}\right)$ based on the distribution of the length of runs of homozygosity by class are described in Table 2 and by chromosome in Figure 2 . $F_{R O H}$ differed significantly among populations across the length categories. The genomic inbreeding coefficients of the shortest $\mathrm{ROH}(0-5 \mathrm{Mb}$; related to ancient kinship) per animal ranged from $0.02 \pm 0.02$ in the Eastern Cape population to $0.08 \pm 0.10$ in North West population. The $F_{R O H}$ of Eastern Cape, Limpopo 
populations increased with category size, whilst decreased in Free State. Gauteng $F_{\mathrm{ROH}}$ decreased from $0.07 \pm 0.09$ to $0.05 \pm 0.09$ for $F_{R O H}>20 \mathrm{Mb}$ and increased at $>20 \mathrm{Mb}$. In KwaZulu-Natal, $F_{R O H}$ increased to $0.08 \pm 0.09$ at $<20 \mathrm{Mb}$ and decreased for $>20 \mathrm{Mb}$ category. Chromosomal distribution of inbreeding showed higher inbreeding levels in chromosome 15, in Gauteng chromosome 19, in KwaZulu-Natal in chromosome 19 followed by chromosome 16. In the North West chromosome 22 and 19 had the highest inbreeding coefficients compared to other chromosomes.

Table 1

Distribution of runs of homozygosity inbreeding coefficients $\left(F_{R O H}\right)$ within each population.

\begin{tabular}{|lllllll|}
\hline $\begin{array}{l}\text { Class } \\
(\mathrm{Mb})\end{array}$ & $\begin{array}{l}\text { Eastern Cape } \\
(\boldsymbol{n}=20)\end{array}$ & $\begin{array}{l}\text { Free State } \\
(\boldsymbol{n}=24)\end{array}$ & $\begin{array}{l}\text { Gauteng } \\
(\boldsymbol{n}=\mathbf{2 8})\end{array}$ & $\begin{array}{l}\text { KwaZulu-Natal } \\
(\boldsymbol{n}=\mathbf{2 5})\end{array}$ & $\begin{array}{l}\text { Limpopo } \\
(\boldsymbol{n}=55)\end{array}$ & $\begin{array}{l}\text { North West } \\
(\boldsymbol{n}=55)\end{array}$ \\
\hline $0-5 \mathrm{Mb}$ & $0.02 \pm 0.02$ & $0.08 \pm 0.09$ & $0.07 \pm 0.09$ & $0.04 \pm 0.07$ & $0.03 \pm 0.04$ & $0.08 \pm 0.10$ \\
\hline $\begin{array}{l}5- \\
10 \mathrm{Mb}\end{array}$ & $0.02 \pm 0.01$ & $0.06 \pm 0.09$ & $0.06 \pm 0.09$ & $0.05 \pm 0.08$ & $0.03 \pm 0.04$ & $0.07 \pm 0.09$ \\
\hline $\begin{array}{l}10- \\
20 \mathrm{Mb}\end{array}$ & $0.02 \pm 0.01$ & $0.06 \pm 0.08$ & $0.05 \pm 0.09$ & $0.08 \pm 0.09$ & $0.03 \pm 0.05$ & $0.07 \pm 0.09$ \\
\hline$>20 \mathrm{Mb}$ & $0.03 \pm 0.01$ & $0.06 \pm 0.04$ & $0.08 \pm 0.12$ & $0.06 \pm 0.05$ & $0.07 \pm 0.03$ & $0.08 \pm 0.09$ \\
\hline
\end{tabular}

\section{Distribution of Runs of Homozygosity (ROH)}

A total of $3383 \mathrm{ROH}$ were identified across populations, although the frequency and length of ROH differed per population. Among the 207 animals, only 1 animal in the Eastern Cape population was lacking ROH, whilst 206 (99.52\%) had at least one ROH longer than $1 \mathrm{Mb}$. The mean number of $\mathrm{ROH}$ per population was 24.36, 23.92, 21.47, 9.13 and 9 in Gauteng, Free State, North West, KwaZulu-Natal, Limpopo and Eastern Cape, respectively (Figure. 3).

The mean ROH length was $7.76 \mathrm{Mb}$ across population. The longest segment (SNP position 39467151 -137516937) was observed in the Gauteng and North West populations was $98.05 \mathrm{Mb}$ in length (1992 SNPs) found on chromosome 1. In KwaZulu-Natal, Free State and Eastern Cape the longest segments were found on chromosome 9 (83.54Mb; 1691 SNPs), chromosome 7 (73.33Mb; 1449 SNPs) and chromosome 7 ( $51.81 \mathrm{Mb} ; 1034 \mathrm{SNPs})$, respectively. ROH shorter than $5 \mathrm{Mb}$ predominated $(n=1949)$ across all populations (Table.1) accounting for $57.61 \%$ of all detected segments and differed per population. These short segments accounted for $72.22 \%$ in the Eastern Cape population, followed by Limpopo ( $n=322 ; 64 \%)$, KwaZulu-Natal ( $n=151 ; 57.20 \%)$, Gauteng $(n=390 ; 57.18 \%)$, North West $(n=$ $645 ; 54.61 \%)$ and Free State $(n=311 ; 5418 \%)$. 
Table 2

Number of runs of homozygosity $(n \mathrm{ROH})$ and length (in $\mathrm{Mb})$ categorised by $\mathrm{ROH}$ length class $\left(\mathrm{ROH}_{1-5 \mathrm{Mb}}\right.$, $\mathrm{ROH}_{5-10 \mathrm{Mb}}, \mathrm{ROH}_{10-20 \mathrm{Mb}}, \mathrm{ROH}_{20-40 \mathrm{Mb}}$ and $\left.\mathrm{ROH}_{>40 \mathrm{Mb}}\right)$.

\begin{tabular}{|lllllll|}
\hline $\begin{array}{l}\text { Class } \\
(\mathrm{Mb})\end{array}$ & $\begin{array}{l}\text { Eastern } \\
\text { Cape } \\
(n=20)\end{array}$ & $\begin{array}{l}\text { Free } \\
\text { State } \\
(n=24)\end{array}$ & $\begin{array}{l}\text { Gauteng } \\
(n=28)\end{array}$ & $\begin{array}{l}\text { KwaZulu-Natal }(n= \\
25)\end{array}$ & $\begin{array}{l}\text { Limpopo } \\
(n=55)\end{array}$ & $\begin{array}{l}\text { North West }(n) \\
=55)\end{array}$ \\
\hline $\mathbf{0 - 5 M b}$ & 130 & 311 & 390 & 151 & 322 & 645 \\
\hline $\mathbf{5 - 1 0 M b}$ & 34 & 146 & 193 & 46 & 100 & 271 \\
\hline $10-20 \mathrm{Mb}$ & 8 & 77 & 68 & 34 & 47 & 163 \\
\hline $20-40 \mathrm{Mb}$ & 7 & 34 & 19 & 27 & 25 & 72 \\
\hline$>40 \mathrm{Mb}$ & 1 & 6 & 12 & 6 & 8 & 30 \\
\hline Total & $\mathbf{1 8 0}$ & $\mathbf{5 7 4}$ & $\mathbf{6 8 2}$ & $\mathbf{2 6 4}$ & $\mathbf{5 0 2}$ & $\mathbf{1 1 8 1}$ \\
\hline
\end{tabular}

The relationship between the mean number of $\mathrm{ROH}$ and the length of the genome covered by $\mathrm{ROH}$ per individual varies considerably among animals and populations. The number of $\mathrm{ROH}$ per chromosome displayed a specific pattern with the larger numbers found for chromosome 1, 2 and 3, a number that tended to decrease with chromosome length, and the smallest number on chromosome 26 with 44 segments. Chromosome 1 had the highest number of ROH and Eastern Cape did not have ROH on chromosome 23 and 28 (Figure. 4).

The proportion of chromosomes covered by $\mathrm{ROH}$ is illustrated in Figure 5. Overall, the highest coverage by $\mathrm{ROH}$ was observed on chromosome $1,2,6$ and 8 at $0.37,0.31,0.38$ and 0.33 , respectively. For the Eastern Cape population, chromosome 4 and $80.07 \%$, whilst Free State, Limpopo and North West had the highest proportion on chromosome 1 with $0.06 \%$. Gauteng and KwaZulu-Natal had the highest at chromosome 6 with 0.06 and $0.08 \%$, respectively.

To identify the genomic regions that were most commonly associated with $\mathrm{ROH}$, the percentage of SNPs in $\mathrm{ROH}$ was assessed by analysing the frequency of a SNP occurring in those $\mathrm{ROH}$ across different individuals (20\%), and this was plotted against the position of the SNP along the chromosome (Figure. 6). The threshold of $70 \%$ and $50 \%$ of the individuals did not yield $\mathrm{ROH}$ islands across populations thus $20 \%$ was used. Several genomic regions were identified that frequently appeared in a ROH within individual animals (Table. 3). We identified $58 \mathrm{ROH}$ islands at the $20 \%$ threshold in the Free State $(n=28)$ and Gauteng $(n=29)$ provinces. No ROH islands were observed in the Eastern Cape, KwaZulu-Natal, North West and Limpopo at the set thresholds. The ROH hotspot with the highest occurrences (SNPs = 149 ) in Gauteng was located on chr7 (7.69Mb). Chromosome position, start and end position of ROH, $\mathrm{ROH}$ length and number of SNPs within the genomic regions of extended homozygosity are reported in Table 3 and Additional file 1, Table S1. A total number of 871 genes inside the ROH islands which include important environmental adaptation and hermo-tolerance genes such as IL 10RB, IL23A, FGF9, IGF1, 
EGR1, MTOR and MAPK3. An additional file 1 shows the KEGG 292 pathways associated with the genes (Table S2) that include Fructose and mannose metabolism, Starch and sucrose metabolism, Vitamin B6 metabolism, Protein export and Phototransduction.

\section{Population structure}

For population structure analysis further quality control parameters were effected in PLINK v1.90 [53]: to remove linked SNPs using the -indep-pairwise 5050.5 command and related individuals (IBS >0.65). The database for population structure included 32886 SNPs and 189 individuals across populations. The plot of the first (PC1) and second eigenvectors (PC2) (Figure 7), shows weak differentiation among the clusters of admixed populations. PC1 shows cluster 1 and 2 consisting of populations of KwaZulu-Natal and Limpopo, respectively. The Eastern Cape population (Cluster 3) revealed a separate cluster (with three outliers). Clusters 4 consists majority of North West and Gauteng, whilst cluster 5 is Free State population.For the further understanding of the degree of admixture within the populations, the ADMIXTURE 1.3 [2] software was used for $\mathrm{K}=2$ to 10 hypothetical ancestral populations, only $\mathrm{K}=2$ to $\mathrm{K}=$ 6 is plotted since no further clusters were observed after $\mathrm{K}=6$ (Figure 8). Assuming two hypothetical ancestral populations, the population from KwaZulu-Natal and Limpopo are revealed, supporting PC 1. The genomes of KwaZulu-Natal and Limpopo shared an origin but have substantial admixture from the Eastern Cape and North West populations. $\mathrm{K}=3$ as the most likely number of genetically distinct groups within our populations presenting the lowest cross-validation error (0.4617), reflecting a clear cluster of the Limpopo populations. Free State, Gauteng and North West showed similar genetic heterogeneity patterns with a considerable level of admixture. North West revealed a high level of within-population genetic differentiation as there are individuals closer to Eastern Cape and another sub-population closer or clustering with Free State. This is also in agreement with the PC 2 coordinate analysis in showing genetic heterogeneity within the population. Moreover, with the increment of the value of $\mathrm{K}(\mathrm{K}=4$ to $\mathrm{K}=$ 6), Free State and Gauteng show a higher level of genetic heterogeneity than the other populations.

\section{Discussion}

The indigenous goat population represents the main links to the development of commercial meat-type breeds and may potentially be relevant as a future source of untapped adaptable genetic material [61]. Therefore, improving our understating of within-ecotype relationships among the major goat producing provinces in South Africa offers a rare opportunity enhancing efficient use of the breeds and implementing conservation programs. This study investigated the indications for population status on inbreeding and runs of homozygosity in the communal indigenous goat population. Data from a previous study [38] enabled a broad geographical coverage of South Africa and represents populations from the major goats producing provinces within the country.

Effective population size $\left(N_{e}\right)$ is a crucial population genetic parameter because of its relationship to the loss of genetic variation, increases in inbreeding, the accumulation of mutations, and the determination 
of the accuracy of genomic selection [21, 5]. Gauteng had the smallest estimated $N_{e}$ among the population and Limpopo had the highest. It was also observed in other studies that effective population size $\left(N_{e}\right)$ showed a reduction to 132 in the Kingdom of Eswatini and highest in South Africa 12 generations ago [61]. It is recommended that to prevent a reduction of the adaptive value in populations, $N_{e}$ values between 50 and 100 animals [40] are accepted to be within a factor of 2 from the true value to avoid inbreeding depression. A study by [10], reported a large $N_{e}(140)$ in local goats breeds, such as those from Africa, Spain and Central-Southern Italy local goats breeds and a small $\mathrm{Ne}(42)$ in the Angora, Boer, Nubian, Cashmere, Saanen and Alpine populations. The introduction of records keeping as part of the conservation strategy for the communal indigenous goat populations and occasional DNA-based controls will help to design mating plans that enabled farmers to control inbreeding and maintain effective population size. This can be particularly the case for breeds with distinctive phenotypic traits, such as horn shape, and sizes and coat colours in the ecotypes.

The rapid increase pattern in Ne may also include bottlenecks associated with domestication, selection and breed formation, and the endangerment of the breed [56]. A study by [38] based on SNP data and using the same method reported large $N_{e}$ for all investigated breeds (ranging from 140 to 348). Furthermore, a study by [39] revealed that the ecotype goat was slightly higher (145) in effective population sizes than the Tankwa and commercial breeds across generations. From a conservation standpoint, the indigenous goat population should top the priority in the population studied due to their diminishing effective population size and increased inbreeding coefficients.

Runs of Homozygosity $(\mathrm{ROH})$ can disclose the genetic relationships among individuals, estimating with high accuracy the autozygosity at the individual and population levels and can elucidate about selection pressure events [54]. If long ROH accumulates in the genome of some individuals, they could seriously impact the overall biological fitness [29], therefore, it was an important objective to investigate and understand the level of homozygosity among the populations. In this study, only 1 animal was lacking $\mathrm{ROH}$, whilst 206 (99.52\%) had at least one ROH longer than $1 \mathrm{Mb}$. The genomic inbreeding coefficients $\left(F_{R O H}\right)$ values found in the study for the Ethiopian goats were $F_{R O H}>1 \mathrm{Mb}$ values [44]. Similar results were found by [44] with more African goats (Cameroon, Ethiopia, Kenya, Madagascar, Malawi, Mali, Mozambique, Nigeria, Tanzania, Uganda, and Zimbabwe) using a clustering algorithm. In this study, differences in terms of total number and length of $\mathrm{ROH}$ were short $(>5 \mathrm{Mb})$ were more abundant $(57.61 \%)$. [48] reported results that showed lower than the $F_{R O H}>2 \mathrm{Mb}$ for Kenya, Uganda, and Mozambique goat breeds when Goat 50K BeadChip was used. On the other hand, the Eastern Cape population showed very low amounts of $\mathrm{ROH}$. This has been suggested to be consistent with recent admixture in the individuals in Chinese cattle [62]. Long segments were abundant in the North West population. [25] recent study revealed a high mean $\mathrm{ROH}$ in the long length category (>30 Mb), and their study suggested that inbreeding is more recent and is indicative of demographic decline. This is possible considering the extensive management systems of goats in the region, where goats are on free-range or are herded with other flocks for some part of the year, although some researchers have argued that such extensive systems may lead to inbreeding [58, 22]. [29] suggested that the lower inbreeding levels in African goats 
could be due to the openness of the breeding systems in most of Africa due to the loose definition of livestock breeds in the region.

One of the main advantages of genomic coefficients is the availability of chromosomal inbreeding coefficients [34]. ROH islands can be defined as genomic regions with reduced genetic diversity and, consequently, high homozygosity around the selected locus that might harbor targets of positive selection and are under strong selective pressure $[51,50]$. ROHs, representing the level of genomic autozygosity, are continuous homozygous segments at the individual and population levels that can be used as a measurement of inbreeding; more in-depth ROHs are the result of demography, natural and artificial selection, and inbreeding [55]. In this study, all the genomic regions associated with ROH were not discussed in details, but the focus was on some selected regions that show associations with several specific traits related to livestock breeding. Five genes were identified and reported to be associated with the important traits of goats (Figure. 5) identified by the selection signature. Overall, the highest coverage by ROH was observed on chromosome 1, 2, 6 respectively. Gene INHA, located on chromosome 2, was reported as a candidate gene for litter size in goats [24]. The PPP1R36 and Heat Shock Protein A2 (HSPA2) (CHI10, 26.402-26.719 Mb) identified in this communal indigenous goats are involved in heat stress response and in other studies, HSPA2, DNAJC24, and DNAJC13 are associated with the heat shock family of genes[55] . The presence of multiple genes associated with heat stress would seem to suggest that the trait is under intense selection pressure in tropically adapted breeds [48].

In accordance with [46], these regions in humans, when they are present in more than $50 \%$ of the individuals of a population, can indicate a strong selection occurrence. The occurrence of ROH hotspots in genomic regions that harbour candidate genes may be involved in selection pressure in response to production and environmental conditions. This study identified $58 \mathrm{ROH}$ hotspots in Gauteng and Free State populations and revealed 871 genes and 292 KEGG pathways. This threshold did not yield any results and only in $20 \% \mathrm{ROH}$ islands were detected in the communal indigenous oat population. The stringent criteria on the communal indigenous goats were used to minimize incorrect discovery of $\mathrm{ROH}$ (false positives) within regions of low marker density. The $20 \%$ threshold has been used in indigenous Chinese pigs, Jinhua [62]. The minimum expected length of homozygous DNA segments is based on the time frame of approximately 25 generations, over which goats are believed to have been characterized in separate breeds [48].

This study further explored the population genetic structure of all South African communal indigenous goat populations. In accordance with our earlier studies [37, 27], the principal component analysis (PCA), the ADMIXTURE analyses based on the SNP array and sequence data sets capitulated the major genetic division among the South African goat populations from two large geographic regions: Eastern Cape and Limpopo. The analysis of genotyping data for communal indigenous goat populations revealed a geographical pattern that underlies the distribution of genomic diversity, and a moderate and weak population structure in the Gauteng, Free State and North West provinces respectively. The genomes of KwaZulu-Natal and Limpopo shared an origin but have substantial admixture from the Eastern Cape and North West populations. Population admixture analysis generated some signals of admixture and 
underlying genetic relationships among the populations [24]. The observation supported a migration route of ancient goat from the northern part of South Africa to the eastern areas of the KwaZulu-Natal, during their migration periods of the Bantu nation. This results can also be influenced by communaltraditional indigenous goat farming system and adaptation to different climatic conditions. However, a more extensive sampling of communal indigenous goat populations that would cover more evenly the other South African provinces is necessary to assess the impact of these factors.

\section{Conclusions}

The results of this study indicated a greater negative impact of inbreeding in recent times which is important for planning conservation strategies. It was revealed that the occurrence of high $N_{e}$ and autozygosity varied largely across ecotypes in communal indigenous goat populations at different recent and ancient events when a genome-wide SNP marker was used. The use of Illumina goat SNP50K BeadChip shows that there was a migration route of ancient goat from the northern part (Limpopo province) of South Africa to the eastern areas of the KwaZulu-Natal, during the migration periods of the Bantu nation was. The communal-traditional indigenous goat farming system and adaptation to different climatic conditions had an influenced on the results in this study. The study deepened the understanding of the conservation status and selection mechanisms of goats in communal indigenous goat production setting. For effective conservation programs and utilisation of South African communal indigenous goat populations, effort should be made to establish a conservation program for the unique genetic resources of indigenous goat populations.

\section{Methods}

\section{Sample collection and genotyping}

A total of 117 communal indigenous goat populations were sampled from Free State $(n=24)$, Gauteng ( $n$ $=28)$, Limpopo $(n=30)$ and North West $(n=35)$ provinces of South Africa. Additionally, genotypes of village populations from Mdladla et al., (2016) representing Eastern Cape $(n=20)$, KwaZulu-Natal ( $n=$ $30)$, Limpopo $(n=30)$ and North West $(n=20)$ provinces were included for further analysis.

All animals were genotyped using the Illumina GoatSNP50 BeadChip (Illumina Inc., San Diego, CA, USA) using the Infinium assay compatible with the Illumina HiScanSQ genotsyping platform at the Agricultural Research Council - Biotechnology Platform in SouthAfrica. A number of quality control measures were applied to all SNPs as follows: SNPs were removed if they had a call rate $<95 \%$, a minor allele frequency (MAF) $<0.05$ and if deviated from the Hardy-Weinberg equilibrium (for a $P$-value cut-off of 0.00001 ), had no assigned genomic locations and on sex chromosomes were also excluded from the analysis. The parameter '-cow' was used to indicate the number (i.e., 29) of autosomes in the goat genome since cow and goat have the same number of autosomes. The final dataset included 47778 SNPs and 207 individuals. 


\section{Genetic diversity indices}

Historical and recent effective population sizes $\left(N_{e}\right)$ for each breed were estimated with the $S \mathrm{NeP}$ [4], which is based on the relationship between linkage disequilibrium (LD), $N_{e}$ and recombination rate. The different SNP marker distance bins used for $\mathrm{r}^{2}$ analysis were used to obtain different estimates of $\mathrm{Ne}$ at different time points by calculating the number of generations $(t)$ in the past as $1 / 2 \mathrm{c}$. To verify the accuracy of the coefficient of inbreeding the genomic coefficient was estimated via two methods. (1) PLINK [52] was used to measure the inbreeding coefficient based on the difference between the observed and expected numbers of homozygous genotypes $\left(F_{\text {HOM }}\right)$ using the function -het. The calculation formula was as follows:

$F_{\text {HOM }}=\left(E_{\text {HOM }}-O_{\text {HOM }}\right) /\left(L-E_{\text {HOM }}\right)$

where $L$ is the number of genotyped autosomal SNPs, $E_{H O M}$ is the number of expected homozygous genotypes and $O_{H O M}$ is the number of observed homozygous genotypes. The inbreeding coefficient based on the proportion of autosomes covered in runs of homozygosity per individual $\left(F_{R O H}\right)$ was determined using detectRUNs [6]. $F_{R O H}$ was calculated as follows:

$F_{R O H}=L_{R O H} / L_{A U T O}$

where $L_{R O H}$ is the total length of ROH on autosomes and $L_{A U T O}$ is the total length of the autosomes covered by SNPs, which was $2450.71 \mathrm{Mb}$. Furthermore, the correlation between $F_{R O H}$ and $F_{H O M}$ was calculated for the four populations.

\section{Distribution of Runs of homozygosity}

Runs of homozygosity $(\mathrm{ROH})$ were identified in every individual using detectRUNS [6] using a sliding window of a specified length or number of homozygous SNPs to scan along with each individual's genotype at each SNP marker position to detect homozygous segments. The parameters and thresholds applied to define a ROH were (i) a sliding window of 50 SNPs across the genome; (ii) the minimum number of consecutive SNPs included in a ROH was 50; (iii) the minimum length of a ROH was set to 1 $\mathrm{Mb}$ to avoid short and common ROH that occur throughout the genome due to LD [55]; and (iv) a maximum of five SNPs with missing genotypes were allowed in a ROH. ROH was divided into five physical length categories (1-5Mb, 5-10Mb, 10-20Mb, 20-30 Mb and <40 Mb). The mean number of ROH per individual, the average length of $\mathrm{ROH}$, the total number of $\mathrm{ROH}$ per animal, the percentage of chromosomes covered by $\mathrm{ROH}$ and mean $\mathrm{ROH}$ were calculated on detectRUNS. The genomic inbreeding coefficient based on $\mathrm{ROHs}\left(F_{\mathrm{ROH}}\right)$ was also calculated as the sum of the length of the autosome covered by ROHs divided by the overall length of the autosome covered by the SNPs as described by [35]. Means and standard deviation (sd) of $F_{R O H}$ were calculated as the sum of the lengths of $F_{R O H 1-5 \mathrm{Mb}}, F_{R O H 5-10 \mathrm{Mb}}$, $F_{R O H 10-20 M b}$ or $<20 \mathrm{Mb}$. 
To identify the genomic regions that were most commonly associated with $\mathrm{ROH}$, the percentage of the occurrences of a SNP in ROH was calculated by counting the number of times the SNP was detected in those $\mathrm{ROH}$ across individuals, and this was plotted against the position of the SNP along the chromosome. This percentage threshold was normalised to $70 \%, 50 \%$ and $20 \%$ of individuals per population to be an indication of a possible hotspot of ROH in the genome. The function of these genes and pathways in which they are involved were assessed using the Kyoto Encyclopedia of Genes and Genomes (KEGG, http://www.genome.jp/kegg/) database and literature search.

\section{Population structure}

Principal component analysis (PCA) was calculated and plotted in Golden Helix SNP and Variation Suite (SVS) V8.1 (Golden Helix, Inc. 2012). ADMIXTURE v1.3.0 program [2] was used for the analysis of ancestry proportions (admixture) with $\mathrm{K}$ set from 2 to 10 . The whole genotype data set was subjected to linkage disequilibrium (LD) pruning using the default parameter of PLINK v1.9 (50 SNPs step 5 SNPs, ${ }^{2}$ 0.5) [52] prior to use in admixture analysis. GENESIS software [9] was used to visualized admixture plots.

\section{Abbreviations}

PCA: Principal component analysis; SNPs: Single nucleotide polymorphism variants; Ne: Effective population; ROH: Runs of homozgosity; $F_{R O H}$ : Genomic inbreeding coefficient based on ROH; FAO: Food and Agriculture Organisation; LD: Linkage disequilibrium; $F$ : inbreeding; IBD: identical-by descent; $F_{I S}$ : Within-population inbreeding coefficients; $n$ : Population size; PC: plot of the first; QTL: $\quad$ Quantitative trait locus; KEGG: Kyoto Encyclopedia of Genes and Genomes; MAF: Minor allele frequency; $F_{H O M}$ : numbers of homozygous genotypes; $E_{\mathrm{HOM}}$ : The number of expected homozygous genotypes; $O_{\mathrm{HOM}}$ : The number of observed homozygous genotypes; $E_{\mathrm{HOM}}$ : The number of expected homozygous genotypes; $L_{R O H}$ : Total length of ROH on autosomes; $L_{\text {AUTO }}$ : Total length of the autosomes

\section{Declarations}

\section{Acknowledgements}

The authors are indebted to Drs. Jullian Japhta and Dr. Noluthando Netnou-Nkoana from the Department of Agriculture, Land Reform and Rural Development, and the research staff of the Agricultural Research Council, Biotechnology Platform for logistical support and assistance during the laboratory work, and Dr. Ayanda Maqhashu from the University of Pretoria for proof reading the manuscript.

\section{Authors' contributions}


Conceptualization: T.C. Chokoe, K. Hadebe, B.J. Mtileni. Formal analysis: T.C. Chokoe, K. Hadebe, F.C. Muchadeyi, E.F. Dzomba, K.A. Nephawe, B.J. Mtileni. Investigation: T.C. Chokoe, K. Hadebe, T.D. Mphahlele, T.C Matelele. Project administration: T.C. Chokoe. Resources: T.C. Chokoe, F.C. Muchadeyi. Supervision: B.J. Mtileni, K. Hadebe, F.C. Muchadeyi. Writing, review and editing: T.C. Chokoe, K. Hadebe, B.J. Mtileni. All authors read and approved the final manuscript.

\section{Funding}

Research grants from the Department of Agriculture, Land Reform and Rural Development's Directorate Genetic Resources and Directorate Policy Research and Support funded the fieldwork data that include data collection, analysis and interpretation that was used for this paper from the project "Characterisation of indigenous goats" as well as full genome sequences of indigenous goats. The first author would like to acknowledge support by the University of Limpopo for allowing him to be their Ph.D. student.

\section{Availability of data and materials}

All data generated or analyzed during this study are included in this published article, and its additional information files are available from the corresponding author on reasonable request. DNA samples were genotyped using the Illumina Goats SNP50 BeadChip using the Infinium assay compatible with the Illumina HiScan SQ genotyping platform at the Agricultural Research Council-Biotechnology Platform in South Africa.

\section{Ethics approval and consent to participate}

Permission for the study and ethical approval were obtained from the animal research ethics committee of both the University of Limpopo and Department of Agriculture, Land Reform and Rural Development. Furthermore, verbal consent was given by the goat owners.

\section{Consent for publication}

Not applicable.

\section{Competing interests}

The authors declare that they have no competing interests.

\section{Author details}


${ }^{1}$ Farm Animal Genetic Resources, Genetic Resources, Department of Agriculture, Land Reform and Rural Development, Private Bag X 973, Pretoria, 0001, South Africa. ${ }^{2}$ School of Agriculture \& Environmental Sciences, Private Bag X 1106, University of Limpopo, Sovenga, Polokwane, 0727, South Africa.

${ }^{3}$ Biotechnology Platform, Agricultural Research Council, Private Bag X5, Onderstepoort, 0110, Pretoria, South Africa. ${ }^{4}$ Discipline of Genetics, School of Life Sciences, University of Kwazulu-Natal, Private BagX 01, Scottsville, 3209 , South African. ${ }^{5}$ Faculty of Science, Department of Animal Science, Private Bag X680, Tshwane University of Technology, Pretoria, 0001, South Africa

\section{References}

1. Ai H, Huang L, Ren J. Genetic diversity, linkage disequilibrium and selection signatures in Chinese and Western pigs revealed by genome-wide SNP markers. PLoS One. 2013; 8(2): e56001.

2. Alexander $\mathrm{DH}$, Novembre J. \& Lange K. Fast model-based estimation of ancestry in unrelated individuals. Genome Research. 2009;19: 1655 - 1664.

3. Alvarenga AB, Rovadoscki GA, Petrini J, Coutinho LL, Morota G, Spangler ML, Pinto LFB, Carvalho GGP, Mourão GB. Linkage disequilibrium in Brazilian Santa Inês breed, Ovis aries. Science Report. 2018;8: 8851.

4. Barbato M, Orozco-Terwengel P, Tapio M, Bruford MW. SNeP: A tool to estimate trends in recent efective population size trajectories using genome-wide SNP data. Frontiers in Genetics. 2015; 6: 109.

5. Berihulay H, Islam R, Jiang L. \& Ma Y. Genome-Wide Linkage Disequilibrium and the Extent of Effective Population Sizes in Six Chinese Goat Populations Using a 50K Single Nucleotide Polymorphism Panel. Animals.2019; 9: 350; DOI:10.3390/ani9060350.

6. Biscarini F, Cozzi P, Gaspa G, Marras G. https://github.com/bioinformaticsptp/detectRUNS/tree/master/detectRUNS. 2018;

7. Bosse M, Megens HJ, Madsen O, Paudel Y, Frantz LA, Schook LB. Regions of homozygosity in the porcine genome: consequence of demography and the recombination landscape. PLOS Genet. 2012; 8:e1003100. DOI: 10.1371/journal.pgen.1003100.

8. Broman KW. \& Weber JL. Long homozygous chromosomal segments in reference families from the centre d'étude du polymorphisme humain. American Journal of Human Genetics. 1999; 65: 1493 1500.

9. Buchmann R. \& Hazelhurst S. Genesis Manual. Johannesburg: University of the Witwatersrand. 2014;

10. Colli L, Milanesi M, Talenti A, Bertolini F, Chen M, Crisà A. Genome-wide SNP profiling of worldwide goat populations reveals strong partitioning of diversity and highlights post-domestication migration routes. Genetics Selection Evolution. 2018; 50:58. DOI: 10.1186/s12711-018- 0422-x. 
11. Curik I, Ferenčaković M, Sölkner J. Inbreeding and runs of homozygosity: a possible solution to an old problem. Livestock Science. 2014; 166: 26 - 34.

12. Deng T, Liang A, Liu J, Hua G, Ye T, Liu S. Genome-Wide SNP Data Revealed the Extent of Linkage Disequilibrium, Persistence of Phase and Effective Population Size in Purebred and Crossbred Buffalo Populations. Frontiers in Genetics. 2019; 9: 688.

13. Dong Y, Xie M, Jiang Y, Xiao N, Du X, Zhang W, Tosser-Klopp G, Wang J, Yang S. \& Liang J. Sequencing and automated whole-genome optical mapping of the genome of a domestic goat (Capra hircus). Nature Biotechnology. 2013; 31:35 - 41.

14. Dube K. Characterization of goat production systems in selected coastal areas of the Eastern Cape Province, South Africa. 2015; PhD Thesis, University of Fort Hare, Alice, South Africa. From: www.netd.ac.za (Accessed 04 October 2017).

15. Ferenčaković M, Hamzic E, Gredler B, Curik I. \& Sölkner J. Runs of homozygosity reveal genome-wide autozygosity in the Austrian fleckvieh cattle. Agric. Conspec. Sci. 2011; 76, 325 -328.

16. Ferenčaković M, Hamziæ E, Gredler B, Solberg TR, Klemetsdal G, Curik I. Estimates of autozygosity derived from runs of homozygosity: empirical evidence from selected cattle populations. Journal of Animal Breeding and Genetics. 2013; 130: 286 - 293.

DOI: $10.1111 /$ jbg.12012.

17. Food and Agriculture Organization of the United Nations (FAO-UN). Draft Second Report on the State of the World's Animal Genetic Resources for Food and Agriculture (Part3), Commission on Genetic Resources for Food and Agriculture, (CGRFA-15/15/Inf.17.2) (Rome). 2015b; From: http://www.fao.org/3/a-mm310e.pdf (Accessed 24 August 2018).

18. Flury C, Tapio M, Sonstegard T, Drogemuller C, Leeb T, Simianer H, Hanotte O, Rieder S. Effective population size of an indigenous Swiss cattle breed estimated from linkage disequilibrium. Journal of Animal Breeding and Genetics. 2010; 127: 339 - 347.

19. Garcia-Gámez E, Gutiérrez-Gil B, Suarez-Vega A, de la Fuente LF, Arranz JJ. Identification of quantitative trait loci underlying milk traits in Spanish dairy sheep using linkage plus combined linkage disequilibrium and linkage analysis approaches. Journal of Dairy Science. 2013; 96: 6059 6069 .

20. Gibson J, Morton NE, Collins A. Extended tracts of homozygosity in outbred human populations. Human Molecular Genetics. 2006; 15: 789 - 795.

21. Goddard M. Genomic selection: prediction of accuracy and maximisation of long term response. Genetica. 2009; 136: 245 - 257. 
22. Gwaze FR, Chimonyo M. \& Dzama K. Communal goat production in Southern Africa: a review. Tropical Animal Health and Production. 2009b; 41: 1157 - 1168.

23. Howrigan D, Simonson M. \& Keller M. Detecting autozygosity through runs of homozygosity: a comparison of three autozygosity detection algorithms. BMC Genomics. 2011; 12: 460. DOI: 10.1186/1471-2164-12-460.

24. Hou J, An X, Li G, Wang Y, Song Y, Cao B. Exploring polymorphisms and their effects on reproductive traits of the INHA and INHBA genes in three goat breeds. Animal Science Journal. 2012; 83: 273 278.

25. Islam R, Li Y, Liu X, Berihulay H, Abied A, Gebreselassie G, Ma Q. \& Ma Y. Genome-Wide Runs of Homozygosity, Effective Population Size, and Detection of Positive Selection Signatures in Six Chinese Goat Breeds. Genes. 2019; 10: 938; DOI:10.3390/genes10110938.

26. Keller MC, Visscher PM. Goddard ME. Quantification of inbreeding due to distant ancestors and its detection using dense single nucleotide polymorphism data. Genetics. 2011; 189: 237 - 249.

27. Lashmar S, Visser C. \& van Marle-Köster E. SNP-based genetic diversity of South African commercial dairy and fiber goat breeds. Small Ruminant Research. 2016; 136: 65 - 71.

28. Liu S, He S, Chen L, Li W, Di J, Liu M. Estimates of linkage disequilibrium and effective population sizes in Chinese Merino (Xinjiang type) sheep by genome-wide SNPs. Genes Genomics. 2017; 39: $733-745$.

29. Manunza A, Noce A, Serradilla JM, Goyache F, Martínez A, Capote J. A genome-wide perspective about the diversity and demographic history of seven spanish goat breeds. Genetics Selection and Evolution. 2016; 48:52. DOI: 10.1186/s1271- $016-0229-6$.

30. Marras G, Gaspa G, Sorbolini S, Dimauro C, Ajmone-Marsan P, Valentini A. Analysis of runs of homozygosity and their relationship with inbreeding in five cattle breeds farmed in Italy. Animal Genetics. 2015; 46: 110-121. DOI: 10.1111/age.12259.

31. Marras G, Gaspa G, Sorbolini S, Dimauro C, Ajmone-Marsam P, Valentini A. Analysis of runs of homozygosity and their relationship with inbreeding in five cattle breeds farmed in Italy. Animal Genetics. 2014; 46:110 - 121.

32. Martin PM, Palhière I, Ricard A, Tosser - Klopp G, Rupp R. Genome Wide Association Study Identifies New Loci Associated with Undesired Coat Color Phenotypes in Saanen Goats. PLoS ONE. 2016; 11, e0152426.

33. Mastrangelo S, Tolone M, Sardina MT, Sottile G, Sutera AM. Genome-wide scan for runs of homozygosity identifies potential candidate genes associated with local adaptation in Valle del 
Belice sheep. Genetics Selection Evolution. 2017; 49 (1): 84. 10.1186/s12711-017-0360-z.hal01635193.

34. Mastrangelo S, Tolone M, Di Gerlando R, Fontanesi L, Sardina MT, Portolano B. Genomic inbreeding estimation in small populations: evaluation of runs of homozygosity in three local dairy cattle breeds. Animal. 2016; 10:746 - 54.

35. McQuillan R, Leutenegger AL, Abdel-Rahman R, Franklin CS, Pericic M, Barac-Lauc L. Runs of homozygosity in European populations. American Journal of Human Genetics. 2008; 83(3): 359372. https://doi.org/10.1016/j.ajhg.2008.08.007 PMID: 18760389.

36. Mdladla K, Dzomba EF. \& Muchadeyi FC. Landscape genomics and pathway analysis to understand genetic adaptation of South African indigenous goat populations. Heredity. 2018; 120(4): 369 - 378 .

37. Mdladla K, Dzomba EF. \& Muchadeyi FC. Characterization of the village goat production systems in the rural communities of the Eastern Cape, KwaZulu-Natal, Limpopo and North West Provinces of South Africa. Tropical Animal Health and Production. 2017; 49: 515 - 527.

38. Mdladla K. Landscape genomic approach to investigate genetic adaptation in South African indigenous goat populations. PhD thesis. 2016;

39. Mdladla K, Dzomba EF, Huson HJ. \& Muchadeyi F.C. Population genomic structure and linkage disequilibrium analysis of South African goat breeds using genome-wide SNP data. Animal Genetics. 2016a; 47: 471 - 482.

40. Meuwissen TH. \& Goddard ME. Multipoint identity-bydescent prediction using dense markers to map quantitative trait loci and estimate effective population size. Genetics. 2007; 176: 2551-60.

41. Morrison JW. A guide to the identification of the natural indigenous goats of Southern Africa. From: http://www.landbou.com/wp.../03/f2297405-a93f-4399-bdb7-6f3de538d75d.pdf. 2007; (Accessed 20 April 2018).

42. Mthi S, Skenjana A, Fayemi P O. Characteristics of small-scale sheep production systems in some communal areas of the Eastern Cape Province, South Africa. International Journal of Livestock Production. 2017; 8: $199-206$.

43. Monau PI, Raphaka K, Zvinorova-Chimboza P. \& Gondwe T. Sustainable Utilization of Indigenous Goats in Southern Africa. Diversity. 2020; 12: 20; DOI:10.3390/d12010020.

44. Nandolo W, Mészáros G, Banda LJ, Gondwe TN, Lamuno D, Mulindwa HA, Nakimbugwe HN, Wurzinger M, Utsunomiya YT, Woodward-Greene MJ, Liu M, Liu G, Van Tassell CP, Curik I, Rosen BD. \& Sölkner J. Timing and Extent of Inbreeding in African Goats. Frontiers in Genetics. 2019; 10:537. DOI: 10.3389/fgene.2019.00537. 
45. Nicoloso L, Bomba L, Colli L, Negrini R, Milanesi M, Mazza R, Sechi T, Frattini S, Talenti A. \& Coizet B. Genetic diversity of Italian goat breeds assessed with a medium-density SNP chip. Genetics Selection Evolution. 2015; 47: 62. DOI 10.1186/s12711-015-0140-6.

46. Nothnagel M, Lu TT, Kayser M, Krawczak M. Genomic and geographic distribution of SNP-defined runs of homozygosity in Europeans. Human Molecular Genetics. 2010; 19: 2927 - 2935.

47. Nyamushamba G B, Mapiye C, Tada O, Halimani TE, Muchenje V. Conservation of indigenous cattle genetic resources in Southern Africa's smallholder areas: turning threats into opportunities-a review. Asian-Australasian Journal of Animal Science. 2017; 30: 603 - 621.

48. Onzima RB, Upadhyay MR, Doekes HP, Brito LF, Bosse M, Kanis E, Groenen MAM. \& Crooijmans RPMA. Genome-Wide Characterization of Selection Signatures and Runs of Homozygosity in Ugandan Goat Breeds. Frontiers in Genetics. 2018; 9: 318. DOI: 10.3389/fgene. 2018. 00318

49. Ouborg NJ, Pertoldi C, Loeschcke V, Bijlsma R, Hedrick PW. Conservation genetics in transition to conservation genomics. Trends Genetics. 2010; 26:177 - 87.

50. Pemberton TJ, Absher D, Feldman MW, Myers RM, Rosenberg NA, Li JZ. Genomic patterns of homozygosity in worldwide human populations. American Journal of Human Genetics. 2012; 91: $275-292$.

51. Peripolli E, Stafuzza NB, Munari DP, Lima ALF, Irgang R, Machado MA. Assessment of runs of homozygosity islands and estimates of genomic inbreeding in Gyr (Bos indicus) dairy cattle. BMC Genomics. 2018; 19:34. DOI: 10.1186/s12864-017-4365-3.

52. Purcell S, Neale B, Todd-Brown K, Thomas L, Ferreira MA, Bender D, Maller J, Sklar P, De Bakker PI. \& Daly MJ.. PLINK: a tool set for whole-genome association and population-based linkage analyses. The American Journal of Human Genetics. 2007; 81: 559 - 575.

53. Purfield DC, Berry DP, McParland S, Bradley DG. Runs of homozygosity and population history in cattle. BMC Genomics. 2012; 13:70. DOI: 10.1186/1471-2156-13-70.

54. Purfield DC, McParland S, Wall E, Berry DP. The distribution of runs of homozygosity and selection signatures in six commercial meat sheep breeds. PLoS One. 2017; 12: e0176780. DOI: 10.1371/journal.pone.0176780.

55. Shi Y \& Manley JL. A complex signaling pathway regulates SRp38 phosphorylation and pre-mRNA splicing in response to heat shock. Molecular Cell. 2007; 28: 79 - 90. DOI: 10.1016/j.molcel.2007.08.028.

56. Shina D, Cho K, Park KD, Lee HJ, Kim H. Accurate estimation of effective population size in the Korean dairy cattle based on linkage disequilibrium corrected by genomic relationship matrix. AsianAustralasia Journal of Animal Science. 2013; 26: 1672 - 1679. 
57. Silió L, Rodríguez MC, Fernández A, Barragán C, Benítez R, Óvilo C. Measuring inbreeding and inbreeding depression on pig growth from pedigree or SNP-derived metrics. Journal of Animal Breeding and Genetics. 2013; 130: $349-360$.

58. Tefera AN, Mekala DG, Mnisi P.E, Mukisira M, Clerkson M, Murungweni C. \& Sebitloane O. Goat production and livelihood systems in the Sekhukhune district of the Limpopo Province, South Africa: Opportunities for commercializing goats and their by-products. Working Document Series 2004; 118. http://search.ebscohost.com/login.aspx?direct=true\&db=lah\&AN= 20043182451\&site=ehost-live (accessed 25 October 2019).

59. Tosser-Klopp G, Bardou P, Bouchez O, Cabau C, Crooijmans R, Dong Y, Donnadieu-Tonon C, Eggen A, Heuven HC. \& Jamli S. Design and characterization of a 52K SNP chip for goats. PloS One. 2014; 9 : e86227.

60. Visser C, Lashmar SF, Van Marle-Koster E, Poli MA. \& Allain D. Genetic diversity and population structure in South African, French and Argentinian Angora Goats from genome wide SNP data. PLoS One. 2016; 11: e0154353.

61. Webb EC. and Mamabolo MJ. Production and reproduction characteristics of South African indigenous goats in communal farming systems. South African Journal of Animal Science. 2004; 34 (1): $236-239$.

62. Xu L, Zhao G, Yang L, Zhu B, Chen Y, Zhang L, Gao X, Gao H, Liu GE, Li J. Genomic Patterns of Homozygosity in Chinese Local Cattle. Scientific Reports. 2019; 9(1): 16977. DOI: 10.1038/s41598019-53274-3

63. Zhang Q, Guldbrandtsen B, Bosse M, Lund MS. \& Sahana G. Runs of homozygosity and distribution of functional variants in the cattle genome. BMC Genomics. 2015; 16:542. DOI: 10.1186/s12864015-1715-x.

64. Zhao F, Wang G, Zeng T, Wei C, Zhang L, Wang H, Zhang S, Liu R, Liu Z, Du L. Estimations of genomic linkage disequilibrium and effective population sizes in three sheep populations. Livestock Science. 2014; 170: 22 - 29.

65. Zvinorova P I. A Genome-Wide Association Study on Mechanisms Underlying Genetic Resistance to Gastrointestinal Parasites in Goats. Ph.D. thesis. 2017;

\section{Table}

Due to technical limitations, table 3 is only available as a download in the Supplemental Files section.

\section{Figures}




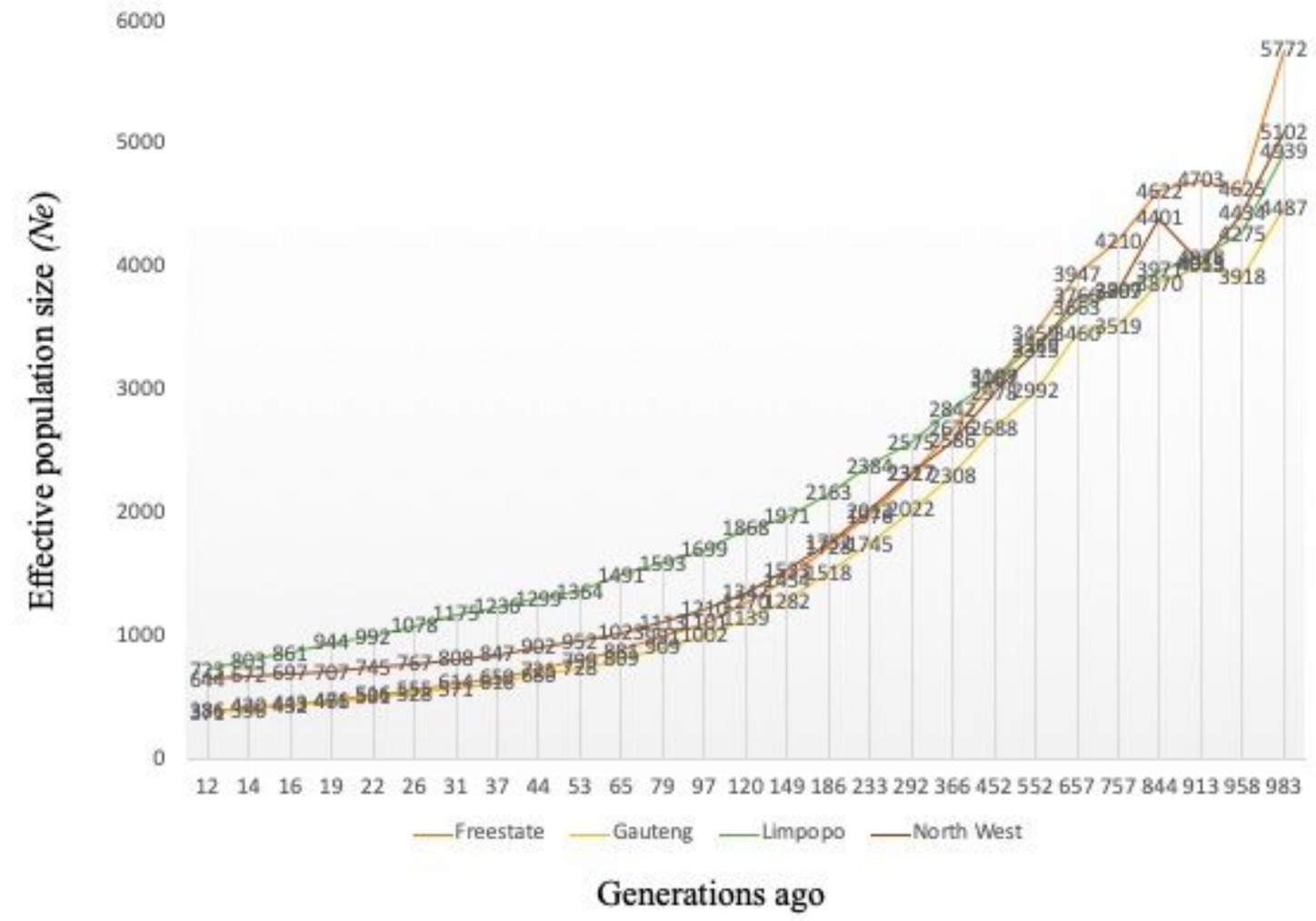

\section{Figure 1}

Effective population size $(\mathrm{Ne})$ for the indigenous village goat populations from Free State, Gauteng, Limpopo and North West. 


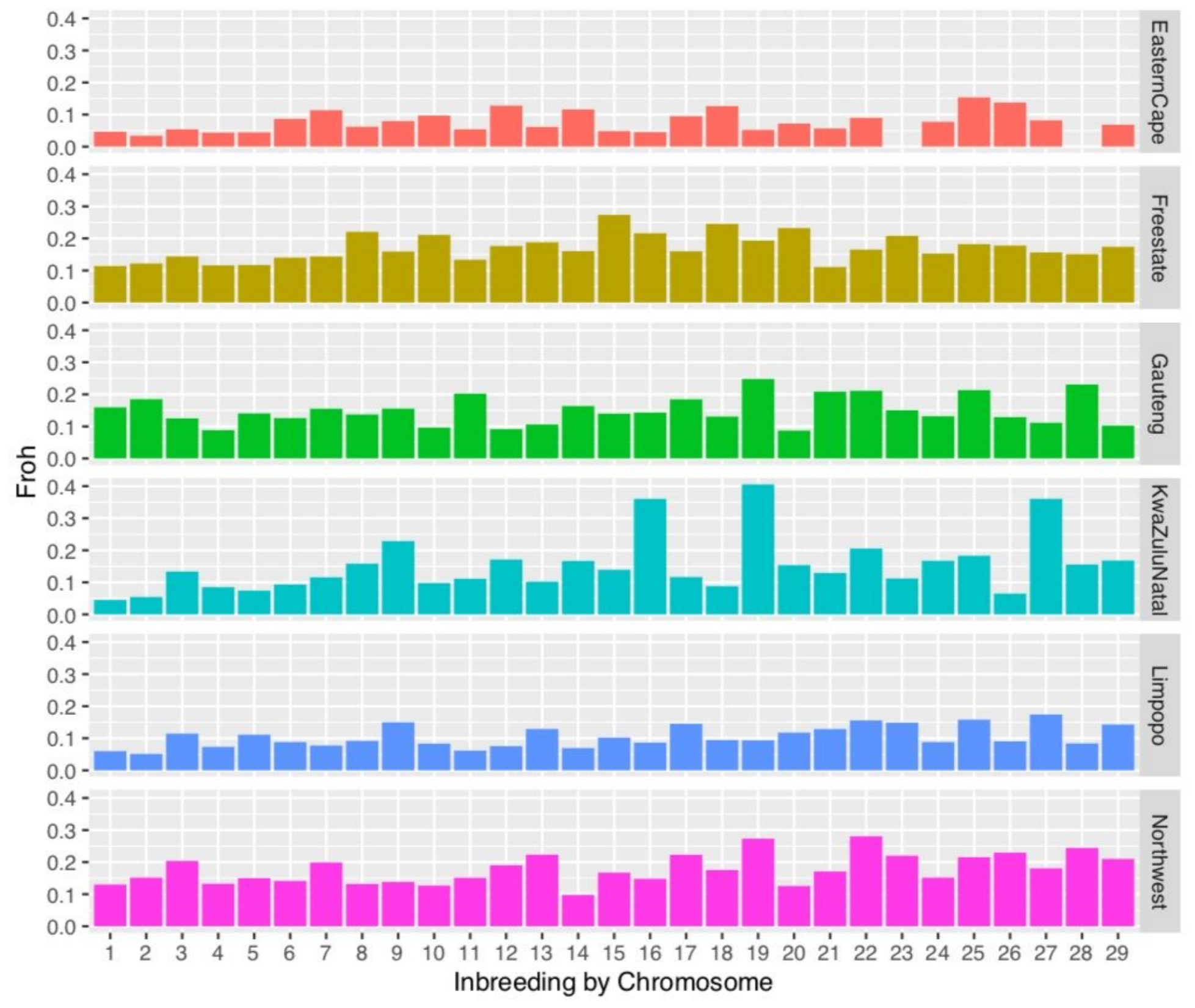

Figure 2

Distribution of inbreeding coefficients $(\mathrm{FROH})$ based on runs of homozygosity $(\mathrm{ROH})$ for each chromosome. 


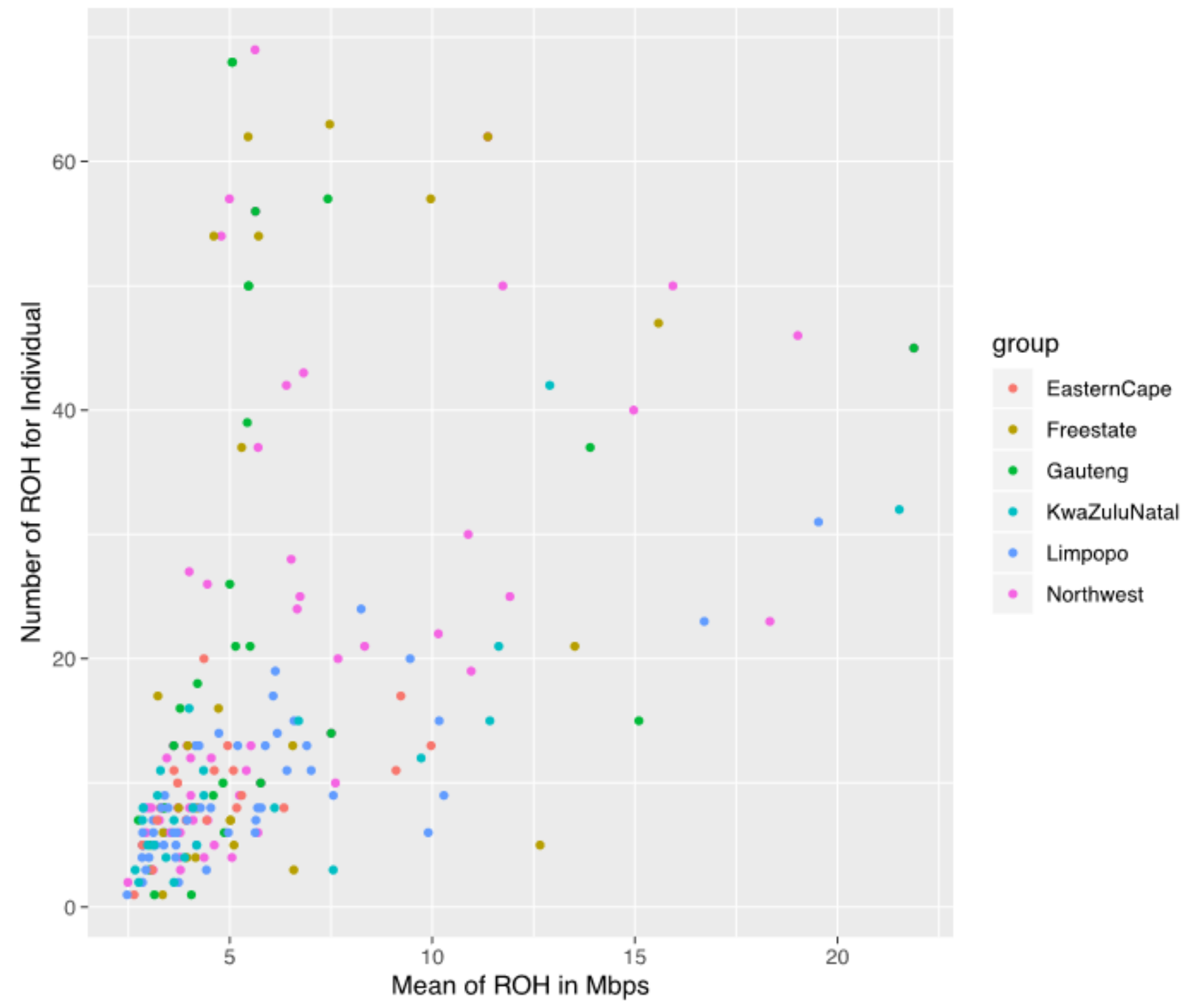

Figure 3

The genomic length with mean runs of homozygosity $(\mathrm{ROH})$ per individual and the number of ROH for individuals. 


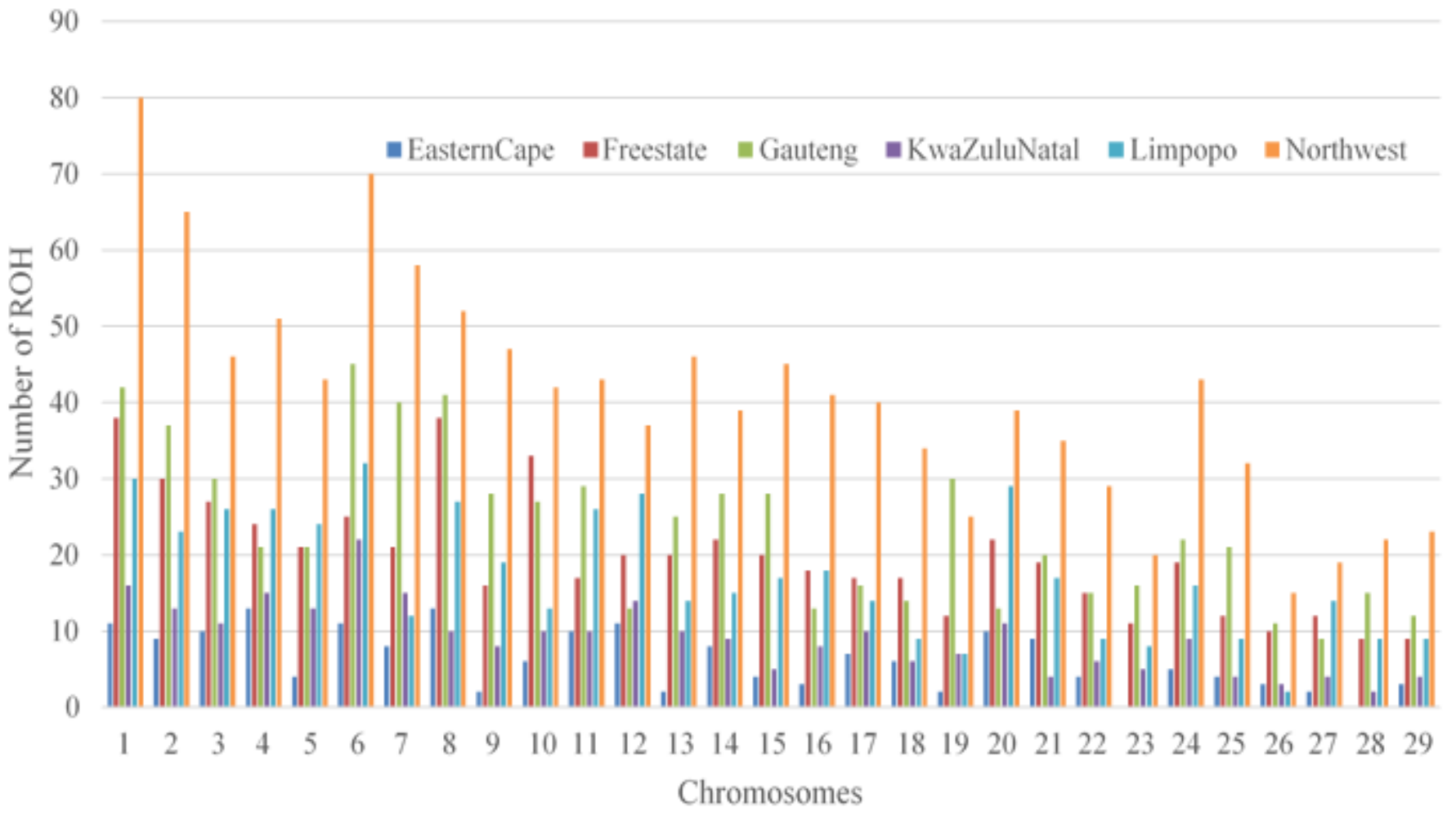

Figure 4

Number of runs of homozygosity $(\mathrm{ROH})$ per chromosome identified across all populations. 

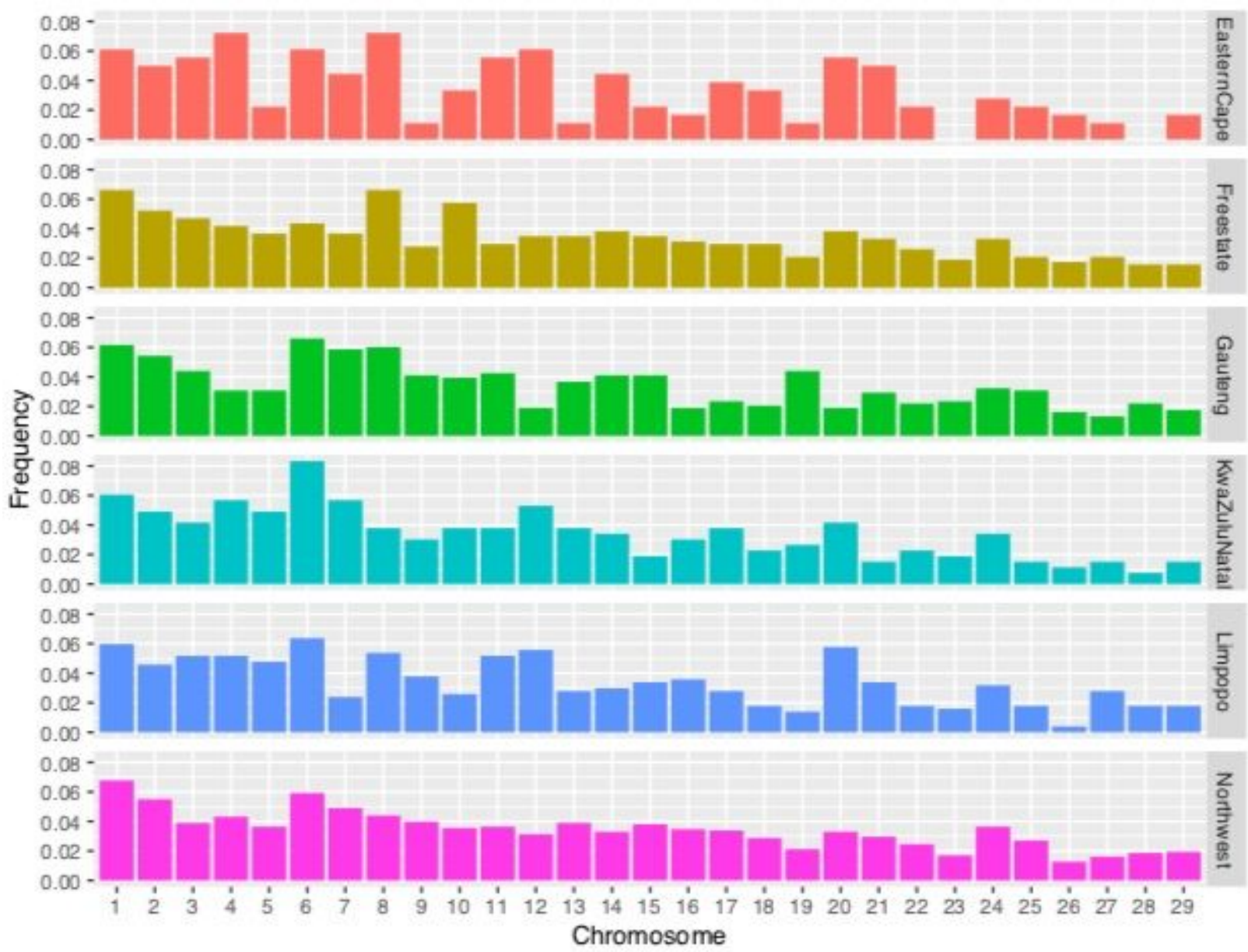

\section{Figure 5}

Frequency of runs of homozygosity $(\mathrm{ROH})$ per chromosome per population

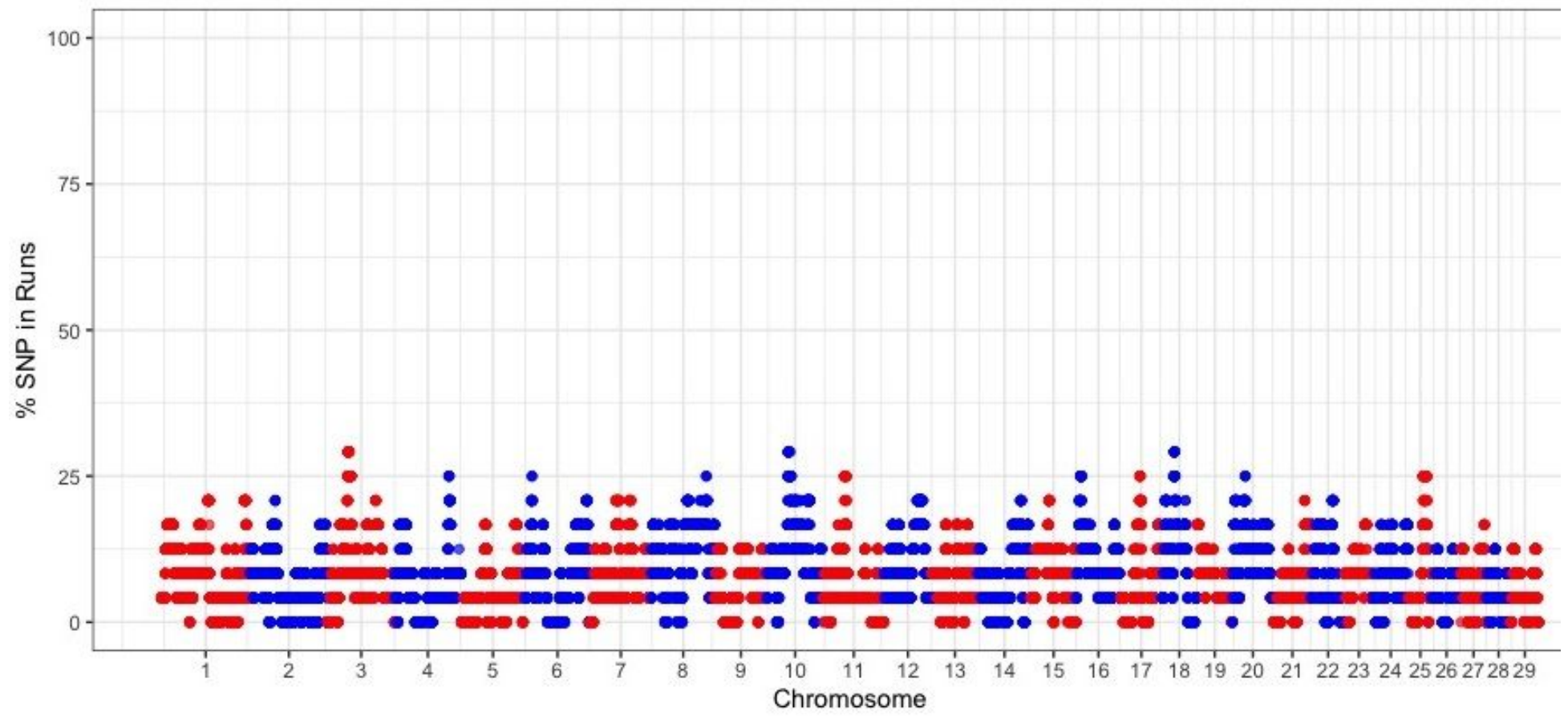

Figure 6 
Manhattan plot of occurrences (\%) of a SNP in ROH across populations. The X-axis represents the distribution of $\mathrm{ROH}$ across the genome, and the $\mathrm{Y}$-axis shows the frequency (\%) of overlapping $\mathrm{ROH}$ shared among samples. The red line indicates the threshold of $20 \%$.

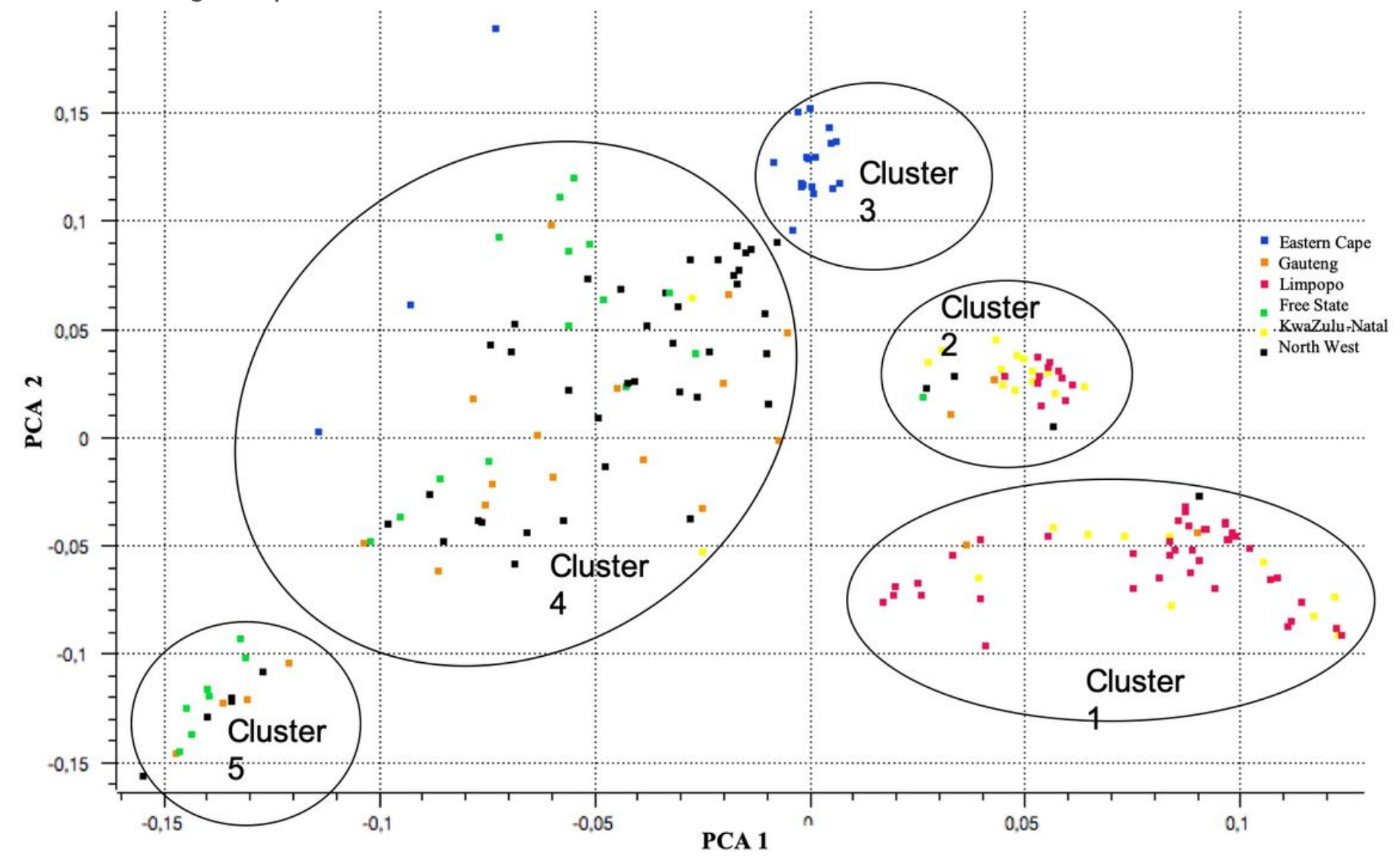

Figure 7

A plot of principal components (PCA) analysis showing differentiations among the clusters of admixtures across six indigenous village goat populations. 

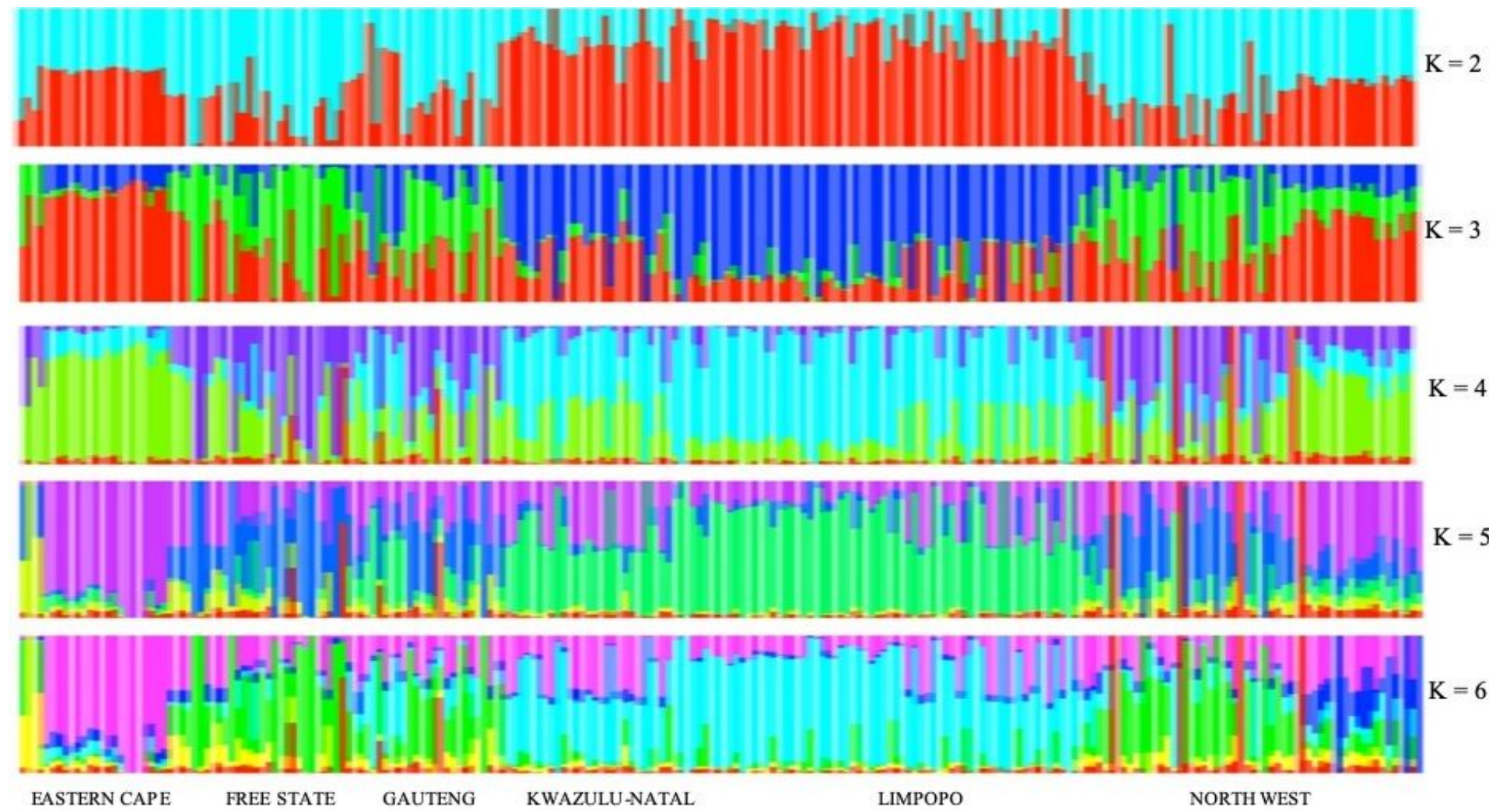

\section{Figure 8}

Clusters inferred from ADMIXTURE at $\mathrm{K}=2-6$. The cluster membership of each sample is shown by the colour composition of the vertical lines, with the length of each colour being proportional to the estimated membership coefficient.

\section{Supplementary Files}

This is a list of supplementary files associated with this preprint. Click to download.

- Table3.docx

- Table3.docx 